\title{
Ball On Plate Balancing System Pada KIT Praktek PID Mata Kuliah Dasar Sistem Kendali
}

\author{
Anwar Mujadin $^{1}$, Dwi Astharini ${ }^{2}$ \\ ${ }^{1,2}$ Program Studi Teknik Elektro, Fakultas Sains dan Teknologi, Universitas Al Azhar Indonesia \\ Komplek Masjid Agung Al Azhar Kebayoran Baru, Jakarta Selatan, Kode Pos 12110
}

Penulis untuk Korespondensi/E-mail: astharini@uai.ac.id

\begin{abstract}
Abstrak - Ball on plate adalah sistem pengendalian cerdas untuk mengarahkan bola yang ada diatas plate sesuai dengan pola gerakan yang diinginkan tanpa menjatuhkan bola. Ball on plate ini digerakan oleh dua buah motor servo sebagai aktuator (keluaran) untuk menentukan posisi bola. Sedangkan kamera ditempatkan diatas plate sebagai sensor (masukan). Image yang ditangkap oleh kamera kemudian diolah oleh labview menjadi pixel posisi $\mathrm{X}$ dan $\mathrm{Y}$. Kerjasama antar mikrokontroler Arduino Uno dan Labview membentuk sebuah pengendalaian close loop system. Pada tulisan ini akan dibahas parameter penting dalam menganalisa rise time, overshoot, settling time dan steady state error pada pengendalian sistem ball on plate menggunakan PID.
\end{abstract}

Kata kunci - Arduino Uno R3 Ball on plate Controller,

Abstract - Ball on the plate is an intelligent control system to steer the ball over the plate that is in accordance with the desired pattern of movement without dropping the ball. Ball on plate is controlled by two servo motors as actuators (output) to determine the position of the ball. While the camera is placed on the plate as a sensor (input). Image captured by the camera and processed by labview to pixel positions $X$ and $Y$. The cooperation among the microcontroller Arduino Uno and Labview configurate a close loop system. In this paper will discuss important parameter in analyzing the rise time, overshoot, settling time and steady state error in the control system using PID ball on the plate.

Keywords - Arduino Uno R3 Ball on plate Controller

\section{PENDAHULUAN}

$\mathrm{K}$ ontrol Proportional Integral Derivative (PID) merupakan salah satu jenis pengontrol yang paling banyak digunakan skala industri saat ini. Implementasi PID banyak diterapkan dalam pengendalian robot, rudal, mobil listrik, conveyor dan lain sebagainya. Pengontrol PID terdiri dari tiga komponen, yaitu komponen Proporsional (P), komponen Integral (I) dan komponen Derivatif (D). Ketiga komponen ini saling melengkapi satu sama lain, sehingga kelemahan-kelemahan pada salah satu komponen dapat ditutupi oleh komponen yang lain. Uniknya ketiga komponen PID tidak dapat berdiri sendiri, satu sama lain akan saling dikombinasikan misalnya pengontrol PI, PD maupun ketiga-tiganya PID. Pengontrol PID akan mengeluarkan aksi kontrol dengan membandingkan kesalahan atau error yang merupakan selisih dari process variable dan setpoint, yang akan digunakan sebagai masukan pengontrol untuk mengeluarkan sinyal kontrol $(\mathrm{u}(\mathrm{t}))$.

Mata kuliah dasar sistem kendali (DSK) adalah salah satu mata kuliah Program Studi Teknik Elektro yang mempelajari sistem kontrol menggunakan PID. Umumnya pihak dosen memberikan materi kelas DSK kemudian dilanjutkan pengujian menggunakan software simulasi numerik Matlab. Pendekatan software menggunakan Matlab hasilnya tidak realistis (optimal) bila tidak menggunakan kit praktek (hardware). Parameter komplek seperti titik berat, gaya gravitasi, arah angin dan momen menjadi salah satu penyebab error dalam 
kontrol PID yang sulit dimasukan kedalam parameter simulasi Matlab.

Penulis telah berhasil merancang bangun sebuah prototipe kit praktek PID berbasis Arduino Uno R3 dan Labview penunjang mata kuliah dasar sistem kendali

Pada tulisan ini akan dibahas hasil penelitian mengenai parameter dalam menganalisa rise time, overshoot, settling time dan steady state error pada pengendalian ball on plate balancing system menggunakan PID.

\section{TINJAUAN PUSTAKA}

\section{Motor Servo}

Motor servo adalah sebuah motor dengan sistem closed feedback di mana posisi dari motor akan diinformasikan kembali ke rangkaian kontrol yang ada di dalam motor servo. Motor servo terdiri dari susunan motor DC, gear, potensiometer dan rangkaian kontrol, seperti yang diperlihatkan pada Gambar 1 dibawah ini [1].

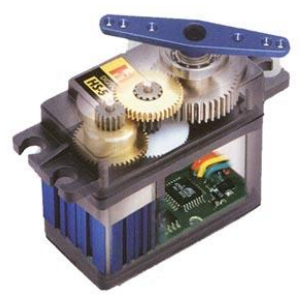

Gambar 1. Susunan komponen motor servo [1].

Sudut dari sumbu motor servo diatur berdasarkan lebar pulsa yang dikirim melalui kaki sinyal dari kabel motor. Motor servo biasanya hanya bergerak mencapai sudut tertentu saja dan tidak kontinyu. Walau demikian, untuk beberapa keperluan tertentu, motor servo dapat dimodifikasi agar bergerak kontinyu Motor servo adalah motor yang mampu bekerja dua arah dimana arah dan sudut pergerakan rotornya dapat dikendalikan hanya dengan memberikan pengaturan duty cycle sinyal pulse width modulation (PWM) pada bagian pin kontrolnya. Sinyal PWM terdiri dari tiga lebar pulsa yaitu $1 \mathrm{~ms}, 1.5 \mathrm{~ms}$ dan $2 \mathrm{~ms}$ dalam perioda konstan $20 \mathrm{~ms}$ seperti yang diperlihatkan pada gambar 2 berikut [1].

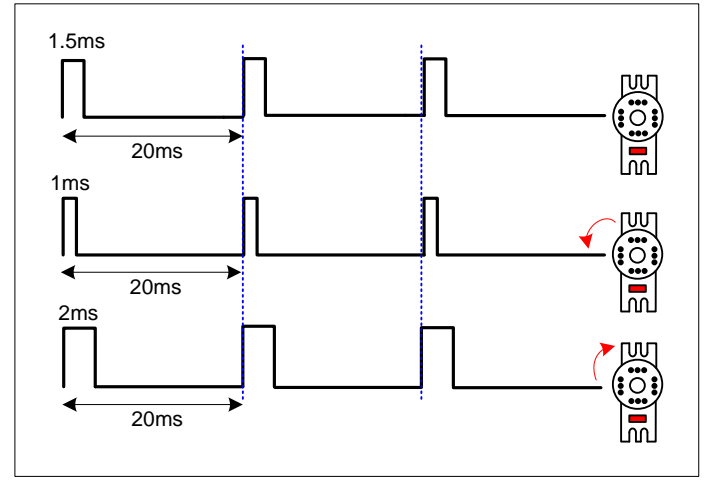

Gambar 2. Sinyal PWM pada servo motor [1].

Motor servo terdiri dari 2 jenis yaitu :

a. Motor Servo Standar $180^{\circ}$, motor servo jenis ini hanya mampu bergerak dua arah (CW dan $\mathrm{CCW}$ ) dengan defleksi masingmasing sudut mencapai $90^{\circ}$ sehingga total defleksi sudut dari kanan - tengah - kiri adalah $180^{\circ}$.

b. Motor servo continuous, motor servo jenis ini mampu bergerak dua arah (CW dan CCW) tanpa batasan defleksi sudut putar (dapat berputar secara kontinyu) [2][3].

\section{Kontrol PID}

Pengontrol PID merupakan salah satu jenis pengontrol yang paling banyak digunakan di industri sekarang ini. Pengontrol PID terdiri dari tiga komponen, yaitu komponen Proporsional (P), komponen Integral (I) dan komponen Derivatif (D). Pengontrol PID akan mengeluarkan aksi kontrol dengan membandingkan kesalahan atau error yang merupakan selisih dari process variable dan setpoint. Secara umum bentuk persamaan pengontrol PID dapat dinyatakan sebagai berikut:

$u(t)=K p e(t)+K_{i} \int_{0}^{t} e(t) d t+K_{d} \frac{d e(t)}{d t}$

dimana:

$\mathrm{u}(\mathrm{t})=$ sinyal output pengendali PID

$\mathrm{Kp}=$ konstanta proporsional

$\mathrm{Ti}=$ waktu integral ;

$\mathrm{Td}=$ waktu derivatif

$\mathrm{Ki}=$ konstanta integral $(\mathrm{Kp} / \mathrm{Ti})$

$\mathrm{Kd}=$ konstanta derivatif (Kp.Td )

$\mathrm{e}(\mathrm{t})=$ sinyal error $=$ referensi - keluaran plant

$=$ set point - nilai sensor 
Diagram Blok dari kontrol PID ditunjukan pada gambar 3 berikut:

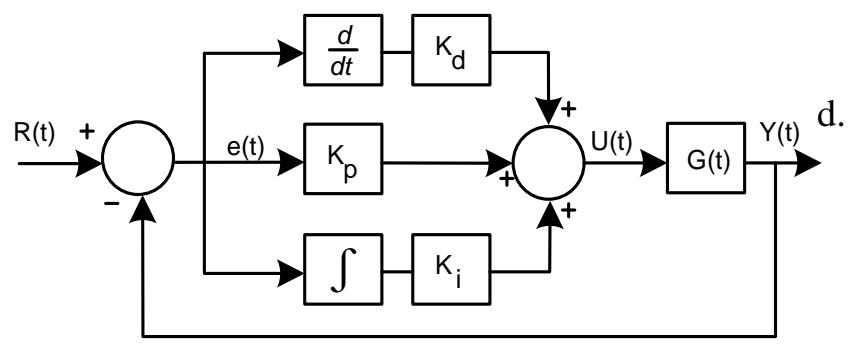

Gambar 3. Kontroler PID

Pada gambar 4 diperlihatkan persamaan dari skematik DC motor.
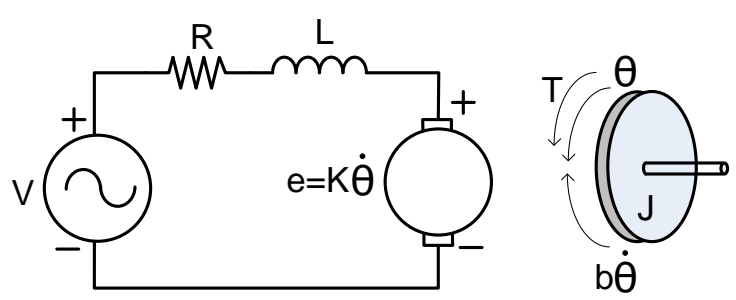

Gambar 4. Persamaan skematik motor DC

\section{Dimana:}

$\mathrm{R}=$ Resistansi $(\mathrm{Ohm})$

$\mathrm{L}=$ Induktansi (Henry)

$\mathrm{J}=$ Momen inersia $\left(\mathrm{kgm}^{2} / \mathrm{s}^{2}\right)$

$\mathrm{T}=$ Torsi $(\mathrm{Nm} / \mathrm{Amp})$

$\mathrm{b} 0=$ konstanta gesekan $(\mathrm{Nms})$

fungsi tranfer dari loop terbuka DC motor dapat ditulis (dari gambar 4) sebagai:

$$
\begin{aligned}
& s(J s+b) Q(s)=K I(s) \\
& (L s+R) I(s)=V(s)-K Q(s)
\end{aligned}
$$

$\frac{Q(s)}{V(s)}=\frac{K}{(J s+b)(L s+R)+K^{2}}$

\section{METODE PENELITIAN}

Kerangka fikir dari metode penilitian:

a. Pengujian karakteristik motor servo kecepatan terhadap sinyal PWM.

b. Mengukur delay time pembacaan sensor (kamera) oleh Labview dari image to pixel dan pixel to XY cordinate. c. Menentukan parameter P,I dan D dengan simulasi Matlab pada karakter servo sesungguhnya, sehingga didapat analisa rise time, overshoot, settling time dan steady state error.

d. Parameter P,I dan D diujicobakan ke mikrokontroler Arduino UNO R3 untuk pengendalian 2 motor servo pada sistem ball on plate

\section{HASIL DAN PEMBAHASAN}

Blok diagram dari pengendalian motor servo pada sistem ball on plate balancing system diperlihatkan pada gambar 5 .

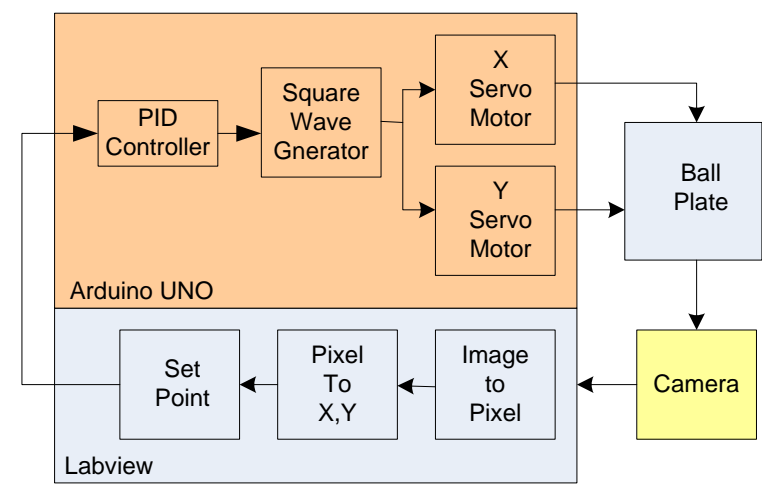

Gambar 5. Pengendalian motor servo pada sistem ball on plate balancing system.

Pada Gambar 6 diperlihatkan ball on plate lengkap dengan mikrokontroler dan 2 buah servo motor

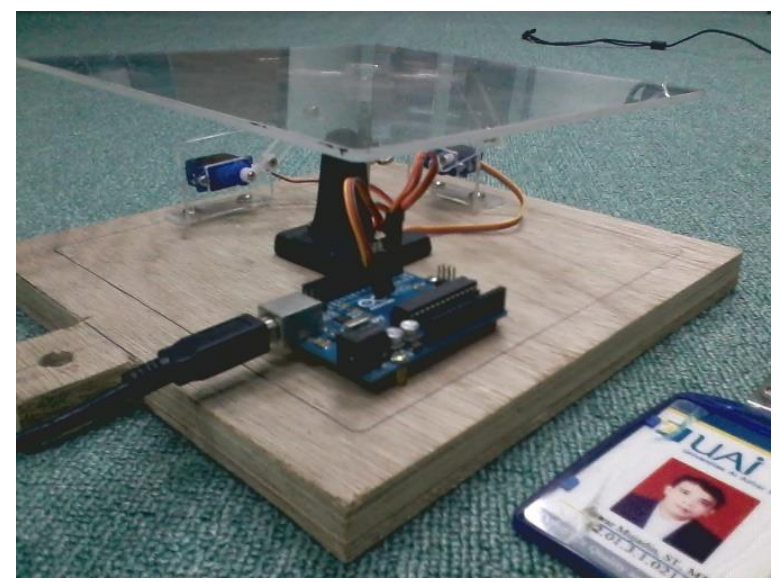

Gambar 6. Ball on plate lengkap dengan mikrokontroler dan 2 buah servo motor

Pada Gambar 7 diperlihatkan ball on plate yang telah dilengkapi dengan kertas ball track. 


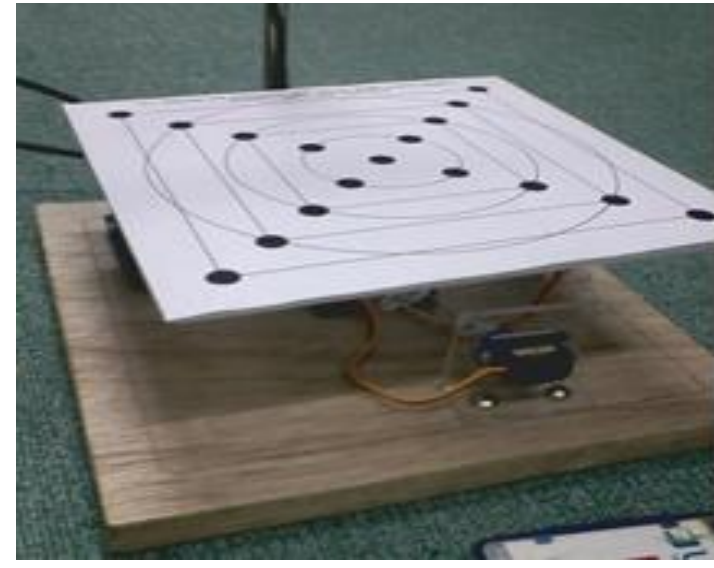

Gambar 7. Ball on plate dilengkapi dengan ball track

Pada gambar 8 diperlihatkan pengendalaian ball on plate balancing system lengkap.

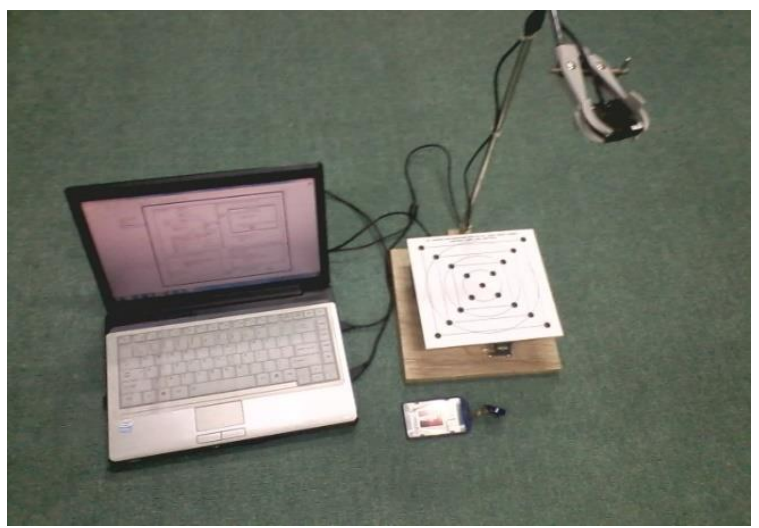

Gambar 8. Sistem pengendalaian ball on plate balancing system lengkap

\section{Respon time}

Motor servo SG90 dalam penelitian ini menggunakan jenis servo standar $180^{\circ}$, bergerak dua arah (CW dan $\mathrm{CCW})$ dengan defleksi masing-masing sudut mencapai $90^{\circ}$. Motor ini memiliki spesifikasi teknis sebagai berikut : Momen inersia $(\mathrm{Jm})=0.01 \mathrm{~kg}^{*} \mathrm{M}^{2} / \mathrm{s}^{2}$, Resistansi $=1 \mathrm{Ohm}$, Induktansi $=0.5$ Henry, Electromotive force constant $\mathrm{Kt}=$ $0.01 \mathrm{Nm} / \mathrm{Amp}$, dan Motor Viscous Friction Constan $(\mathrm{Beq})=0.1 \mathrm{Nms}$.

Dengan menggunakan simulink Matlab, fungsi alih dari kontrol PID diperlihatkan pada Gambar 9.

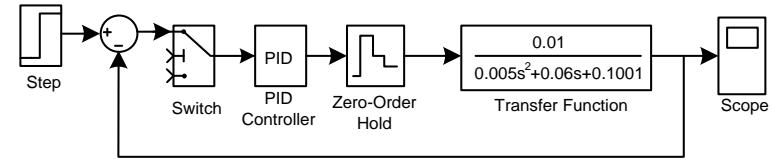

Gambar 9. Fungsi alih kontroler proposional PID

Hasil Matlab untuk $\mathrm{Kp}=100, \mathrm{Ki}=0$ dan $\mathrm{Kd}=0$, grafik fungsi alih diperlihatkan pada gambar 10 berikut:

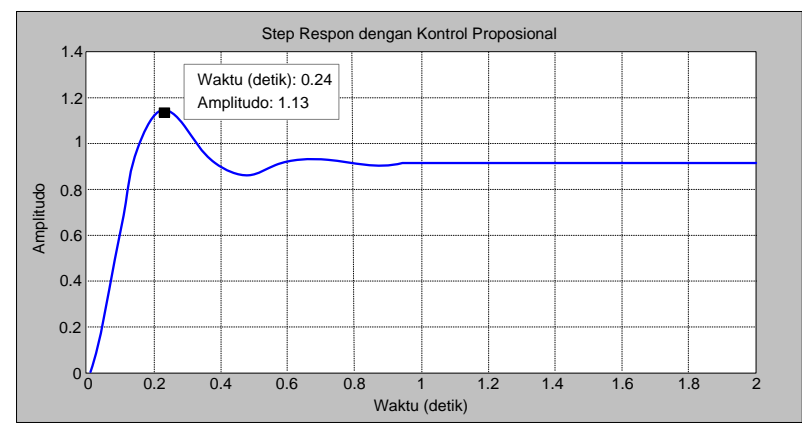

Gambar 10. Hasil Matlab Kp=100; Ki=0; Kd=0

Terlihat pada gambar 10, bahwa overshoot kurang lebih $25 \%$ dengan settling time 0.37 detik dan steady state error sistem adalah 0.1.

Hasil Matlab untuk $\mathrm{Kp}=100, \mathrm{Ki}=1$ dan $\mathrm{Kd}=1$, grafik fungsi alih diperlihatkan pada gambar 11 berikut:

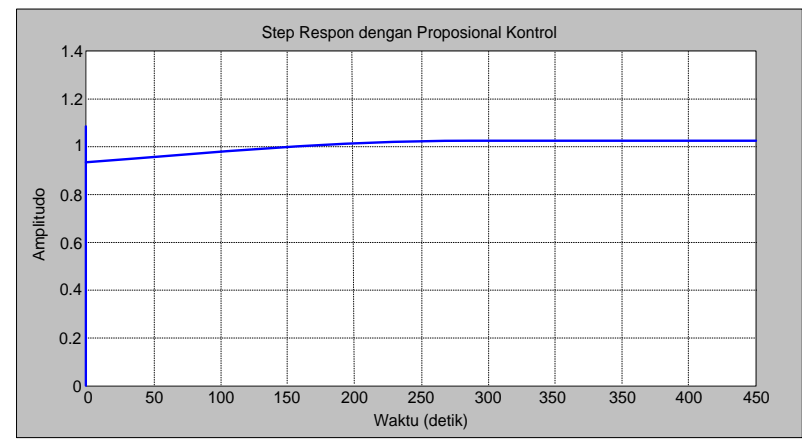

Gambar 11. Hasil Matlab Kp=100; Ki=1; Kd=1

Dari gambar 11 terlihat settling time menjadi 400 detik, sangat kurang bagus dalam parameter pengendalian.Terlihat juga pada detik $\mathrm{t}=0$ sistem sangat tidak stabil.

Hasil Matlab untuk $\mathrm{Kp}=100, \mathrm{Ki}=200$ dan $\mathrm{Kd}=10$, grafik fungsi alih diperlihatkan pada gambar 12 berikut: 


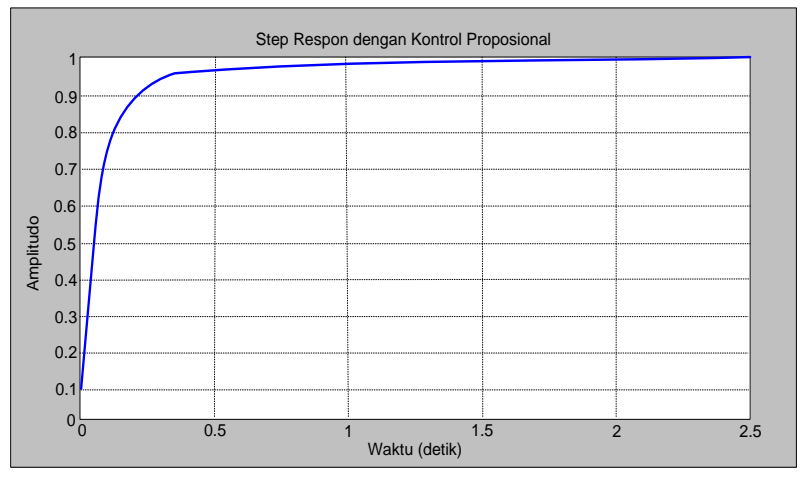

Gambar 12. Hasil Matlab $\mathrm{Kp}=100 ; \mathrm{Ki}=200 ; \mathrm{Kd}=10$

Terlihat pada gambar 12, bahwa overshoot $0 \%$ steady state error sistem adalah 0 dan settling time di 2 detik. Parameter kontroler PID seting ini sangat baik untuk pengendalian motor servo.

Selain fungsi alih menggunakan step respon, perlu diteliti juga kecepatan motor servo baik menggunakan kontroller PID maupun tanpa kontroler PID.

Pada gambar 13 diperlihatkan step respon pada servo motor tanpa menggunakan PID kontroler.

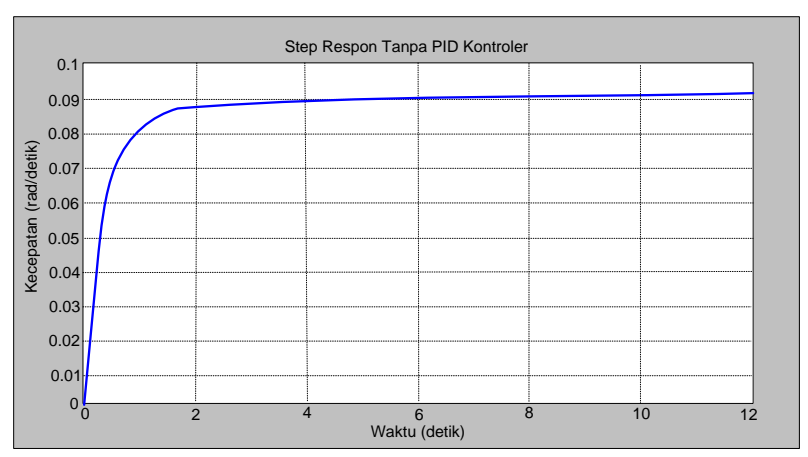

Gambar 12. Step motor respon pada servo motor tanpa menggunakan PID kontroler

Dari gambar 12 terlihat bahwa steady state error sistem bertambah sampai 0.9 tiap 0.1 terhadap fungsi waktu. Ini bertanda bahwa tidak akan mungkin terjadi pergerakan (kecepatan motor) tanpa menggunakan PID.

Pada gambar 13 diperlihatkan step respon motor servo dengan PID kontroler $\mathrm{Kp}=100$; $\mathrm{Ki}=200 ; \mathrm{Kd}=10$

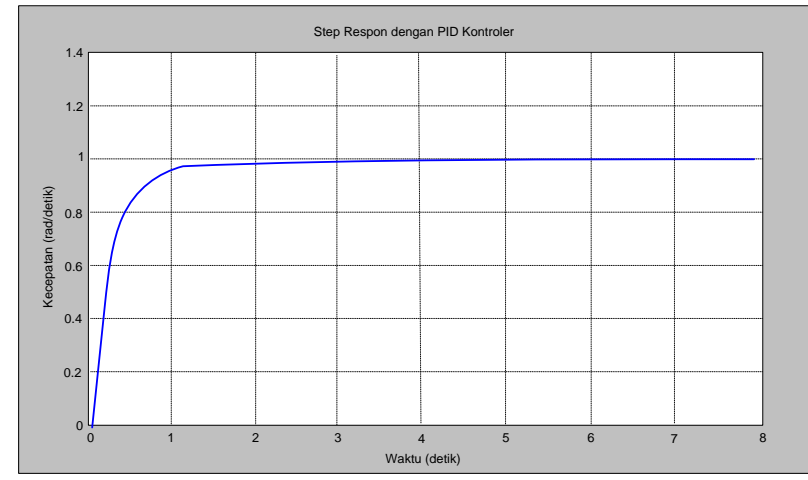

Gambar 13. Step motor respon pada servo motor dengan menggunakan PID kontroler. $\mathrm{Kp}=100 ; \mathrm{Ki}=200 ; \mathrm{Kd}=10$

Terlihat pada gambar 13, bahwa overshoot $0 \%$ steady state error sistem adalah 0 dan settling time di 2 detik. Parameter kontroler PID seting ini sangat baik untuk pengendalian kecepatan motor servo.

\section{KESIMPULAN}

Dari hasil percobaan dan analisa ditunjukan bahwa parameter PID kontroler pada $\mathrm{Kp}=100$; $\mathrm{Ki}=200 ; \mathrm{Kd}=10$, memberikan hasil unjuk kerja yang optimal pada pengendalain servo motor terutama pada respon tangap dan kecepatan (velocity) untuk motor jenis servo SG90 yang memiliki fitur standar $180^{\circ}$, bergerak dua arah (CW dan $\mathrm{CCW}$ ) dengan spesifikasi teknis momen inersia $(\mathrm{Jm})=0.01 \mathrm{~kg}^{*} \mathrm{M}^{2} / \mathrm{s}^{2}$, Resistansi $=1$ Ohm, Induktansi $=0.5$ Henry, Electromotive force constant $\mathrm{Kt}=$ $0.01 \mathrm{Nm} / \mathrm{Amp}$, dan Motor Viscous Friction Constan $(B e q)=0.1$ Nms. Parameter ini dapat di masukan dalam coding Arduino UNO R3 sebagai referensi pengendalian motor servo menggunakan PID.

Parameter seting PID ini telah memenuhi syarat pada pengendalian motor servo dimana settling time kurang dari 2 detik, overshoot system dibawah $5 \%$ dan steady state error dibawah $1 \%$.

\section{UCAPAN TERIMA KASIH}

Penelitian ini didukung oleh Prodi Elektro Fakultas Sains Dan Teknologi Universitas Al Azhar Indonesia, didanai $\mathrm{O}=$ oleh Research Grant 2015-2016 LP2M UAI 


\section{DAFTAR PUSTAKA}

[1] Dorf, Richard C. and Robert H. Bishop, Modern Control Systems, 9th ed., Prentice-Hall Inc.,New Jersey-07458, USA, 2001, Chapters 1, 5, pp. 1-23, pp. 173-206.

[2] Y. Zhang, L.S. Shieh, C.M. Akujuobi \& W. Ali, Digital PID controller design for delayed multivariable systems, Asian Journal of Control, 6(4), 2004.

[3] A. Zeeshan and N. Nauman, Design control and implementation of a ball on plate balancing system, Proceedings of 2012 9th International Bhurban Conference on Applied Sciences \& Technology (IBCAST), IEEE conference Publication Pages: 22 - 26,2012

[4] Ehsan Ali and Narong Aphiratsakun, ball on plate balancing robot, IEEE International Conference on Robotics and Biomimetics (ROBIO), page 2031 - 2034, 2015. 